\title{
Saúde bucal em usuários da atenção primária: análise qualitativa da autopercepção relacionada ao uso e necessidade de prótese dentária
}

I ${ }^{1}$ Helena Weschenfelder Corrêa, ${ }^{2}$ Fernando Valentim Bitencourt, ${ }^{3}$ Alex Vettori Nogueira, ${ }^{4}$ Ramona Fernanda Ceriotti Toassi I

Resumo: Este estudo de caso de abordagem qualitativa propôs-se a analisar a autopercepção da saúde bucal em usuários da Atenção Primária de Porto Alegre que usam e/ou necessitam de prótese dentária. A coleta de dados aconteceu por meio da análise de prontuários odontológicos, diários de campo e entrevistas domiciliares semiestruturadas com 70 usuários do serviço de saúde nas faixas etárias de 15 a 19, 35 a 44 e 65 a 74 anos, que usam e/ou necessitam de prótese dentária (amostra intencional por saturação). Os relatos das entrevistas foram interpretados pela análise de conteúdo de Bardin com o apoio do software ATLAS.ti. A autopercepção positiva de saúde bucal foi percebida por adultos e idosos usuários de próteses bem adaptadas, que não machucavam a boca e não interferiam na mastigação, na fala e na comunicação. Houve grande valorização do uso de próteses pela possibilidade da reabilitação bucal. O desejo do uso de próteses esbarrou em seu alto custo e no acesso limitado a tal procedimento no serviço público do município. Essas informações permitem a análise do significado da saúde bucal para os usuários do Sistema Único de Saúde, podendo ser utilizadas como uma ferramenta de avaliação complementar da necessidade de tratamento odontológico.

Palavras-chave: autopercepção; saúde bucal; prótese dentária; atenção primária à saúde; pesquisa qualitativa.
1 Universidade Federal do Rio Grande do Sul. Graduação em Odontologia. Porto Alegre-RS, Brasil (helenawes@gmail.com)

2 Universidade Federal do Rio Grande do Sul. Graduação em Odontologia. Porto Alegre-RS, Brasil (fernando.bitencourt@ ufrgs.br).

${ }^{3}$ Unidade de Saúde da Família Nossa Senhora de Belém. Hospital Divina Providência. Porto Alegre-RS, Brasil (alevettori@hotmail.com).

${ }^{4}$ Faculdade de Odontologia Mestrado Profissional Ensino na Saúde da Faculdade de Medicina. Universidade Federal do Rio Grande do Sul. Porto Alegre-RS, Brasil (ramona. fernanda@ufrgs.br).
Recebido em: 21/07/2015 Aprovado em: 08/12/2015 


\section{Introdução}

A condição de saúde bucal da população adulta no Brasil e, sobretudo, idosa carrega a herança de um modelo assistencial centrado em práticas mutiladoras e com baixo poder de resolutividade, o que resultou em uma precária realidade, com ausência de dentes e alta demanda por acesso a serviços protéticos e demais tratamentos odontológicos (BRASIL, 2011; MARTINS et al., 2008; MOREIRA et al., 2005).

Dados epidemiológicos de saúde bucal, em 2002-2003, mostraram a perda dentária precoce no Brasil como um importante problema que se inicia já na primeira faixa etária, de 15 a 19 anos, com agravo gradual nas demais idades. A necessidade protética também teve início entre os adolescentes, gerando o mesmo quadro de maiores necessidades entre adultos e idosos. Esses problemas culminam com o edentulismo, que continua sendo um problema grave no país (BRASIL, 2004a).

Em 2010, os resultados do mais recente levantamento epidemiológico nacional indicaram que a situação de saúde bucal melhorou, comparando com 2003, sendo identificada uma importante redução de $52 \%$ nas necessidades de prótese entre os adolescentes. Para os adultos, a necessidade de algum tipo de prótese ocorreu em $69 \%$ dos casos, sendo que $41 \%$ necessitavam de prótese parcial em um maxilar. Em 1,3\% dos casos, houve a necessidade de prótese total em pelo menos um maxilar. Importante destacar que esse percentual, em 2003, era de 4,4\%. Nos idosos (65 a 74 anos), os números encontrados ficaram muito próximos dos encontrados em 2003 e representaram um contingente de mais de três milhões de idosos que necessitavam de prótese total em pelo menos um maxilar e mais de quatro milhôes que necessitavam de prótese parcial (BRASIL, 2011).

Ausências dentárias, bem como a utilização de próteses inadequadas, resultam em problemas funcionais, como comer, mastigar e falar, e sociais, como mudanças no comportamento, dificuldade de acesso ao mercado de trabalho e insatisfação/rejeição da aparência física. Tais condições podem ter graves repercussões, como diminuição da autoestima, dificuldades de socialização, sensação de envelhecimento e sentimento de constrangimento e humilhação (VASCONCELOS et al., 2012; SILVA et al., 2010; VARGAS; PAIXÃO, 2005).

Relaciona-se a autopercepção em saúde ao conceito de qualidade de vida, entendendo-a como a interpretação das experiências e do estado de saúde no 
contexto da vida diária. Baseia-se nas informações e nos conhecimentos de saúde e doença, modificados pela experiência, normas sociais e culturais de cada indivíduo (VASCONCELOS et al., 2012). A autopercepção da saúde bucal, assim, é um indicador subjetivo complexo, que combina componentes físicos, emocionais e do bem-estar individual, e que é diretamente influenciado por razões sociais, econômicas e psicológicas que só podem ser explicadas e compreendidas quando os pacientes são ouvidos e quando os seus autodiagnósticos e suas opiniōes são levados em consideração (VALE; MENDES; MOREIRA, 2013; MENDONÇA; SZWARCWALD; DAMACENA, 2012; MARTINS; BARRETO; PORDEUS, 2008).

A temática "autopercepção da saúde bucal" tem sido avaliada em diferentes populações, como agentes comunitários de saúde (BOMBARDA-NUNES; MIOTTO; BARCELLOS, 2008), funcionários universitários técnicoadministrativos (SCALCO et al., 2013), pacientes com hanseníase (ALMEIDA et al., 2013), gestantes (SILVA; ROSELL; VALSECKI JÚNIOR, 2006), indivíduos dentados de 20 anos ou mais (LOCKER, 2009) e idosos (VASCONCELOS et al., 2012; ESMERIZ; MENEGHIM; AMBROSANO, 2012; SILVA et al., 2011; MARTINS et al., 2011; MARTINS et al., 2010; SILVA; SOUSA; WADA, 2005; SILVA; FERNANDES, 2001). Os instrumentos de aferição mais utilizados na maior parte desses estudos são indicadores sociodentais, quantitativos (questionário estruturado), que englobam os aspectos psicológicos e sociais, por intermédio da autopercepção e do levantamento dos impactos causados na qualidade de vida de pessoas ou populações, como o Oral Health Impact Profile (OHIP) e o Geriatric Oral Health Assesment Index (GOHAI). Poucos são, no entanto, os estudos de abordagem qualitativa encontrados na literatura avaliando a autopercepção da saúde bucal (HAIKAL et al., 2011; CARVALHO et al., 2011).

Considerando a importância do conhecimento de aspectos subjetivos que envolvem o saber construído no cotidiano de vida das pessoas para a resolutividade do cuidado em saúde e entendendo a boca como um território que apresenta contornos e significações diferenciados (BOTAZZO, 2006), o presente estudo propôs-se a analisar a autopercepção da saúde bucal em usuários da Atenção Primária que usavam e/ou necessitavam de prótese dentária. 


\section{Metodologia}

Estudo fundamentado nos preceitos metodológicos da pesquisa qualitativa, caracterizando-se como um estudo de caso (YIN, 2010) cuja população foi de usuários do serviço de saúde bucal da Atenção Primária / Estratégia Saúde da Família de Porto Alegre - Rio Grande do Sul, nas faixas etárias de 15 a 19 anos, 35 a 44 anos e 65 a 74 anos, que utilizavam e/ou necessitavam de prótese dentária.

As faixas etárias selecionadas para o estudo basearam-se nas recomendações da Organização Mundial de Saúde (OMS) em relação aos grupos etários sugeridos para a composição das amostras em levantamentos epidemiológicos. Elas também foram utilizadas nos dois últimos levantamentos epidemiológicos das condições de saúde bucal do Brasil (BRASIL, 2004a; 2011).

O estudo foi aprovado pelos Comitês de Ética em Pesquisa da Universidade Federal do Rio Grande do Sul (parecer 400.170) e da Prefeitura Municipal de Porto Alegre (parecer 603.419-0). A coleta de dados foi realizada em dois momentos: análise dos prontuários odontológicos dos usuários da Atenção Primária em uma Unidade de Saúde da Família (USF), para identificação dos dados sobre o uso e necessidade de prótese dentária; e entrevistas domiciliares, para avaliar a autopercepção da saúde bucal.

Agregaram-se ao corpus de análise, registros do diário de campo, construído a partir de observações e conversas informais dos pesquisadores com os usuários do serviço e agentes comunitários de saúde, durante a coleta de dados. Os registros do diário foram analisados junto com o material textual das entrevistas domiciliares, seguindo o mesmo método.

\section{Análise de prontuários odontológicos}

A consulta aos prontuários odontológicos aconteceu na USF investigada e foi realizada pelos pesquisadores, assegurando a privacidade e o anonimato dos sujeitos de pesquisa. Teve o objetivo de identificar os usuários desse serviço de Atenção Primária que usavam e/ou necessitavam de prótese dentária. $\mathrm{O}$ exame clínico registrado no prontuário foi realizado pelo dentista da Unidade de Saúde, seguindo o Protocolo de Atenção em Saúde Bucal de Porto Alegre (PORTO ALEGRE, 2014).

Foram considerados usuários de prótese aqueles indivíduos que apresentavam registrada no exame clínico bucal do prontuário a presença, em qualquer das arcadas, de reabilitação protética do tipo prótese total (PT), prótese parcial 
removível (PPR) ou fixa (PF). Para a avaliação da necessidade de prótese, foi considerada a presença de perdas dentárias. Nos casos de ausência(s) parcial(is), a PPR foi indicada; para as ausências dentárias totais, indicou-se a PT.

Um mesmo indivíduo foi incluído na categoria "uso e necessidade de prótese", simultaneamente, quando em uma das arcadas ele já possuía prótese, necessitando, porém, reabilitação protética na outra arcada.

Os critérios utilizados para a seleção da amostra estão apresentados na figura 1. Ao final, 141 prontuários de usuários da Atenção Primária nas condiçôes "uso", "uso e necessidade" e "necessidade" de prótese dentária foram selecionados.

Figura 1. Critérios de seleção da amostra de usuários do serviço de saúde bucal na Unidade de Saúde da Família estudada

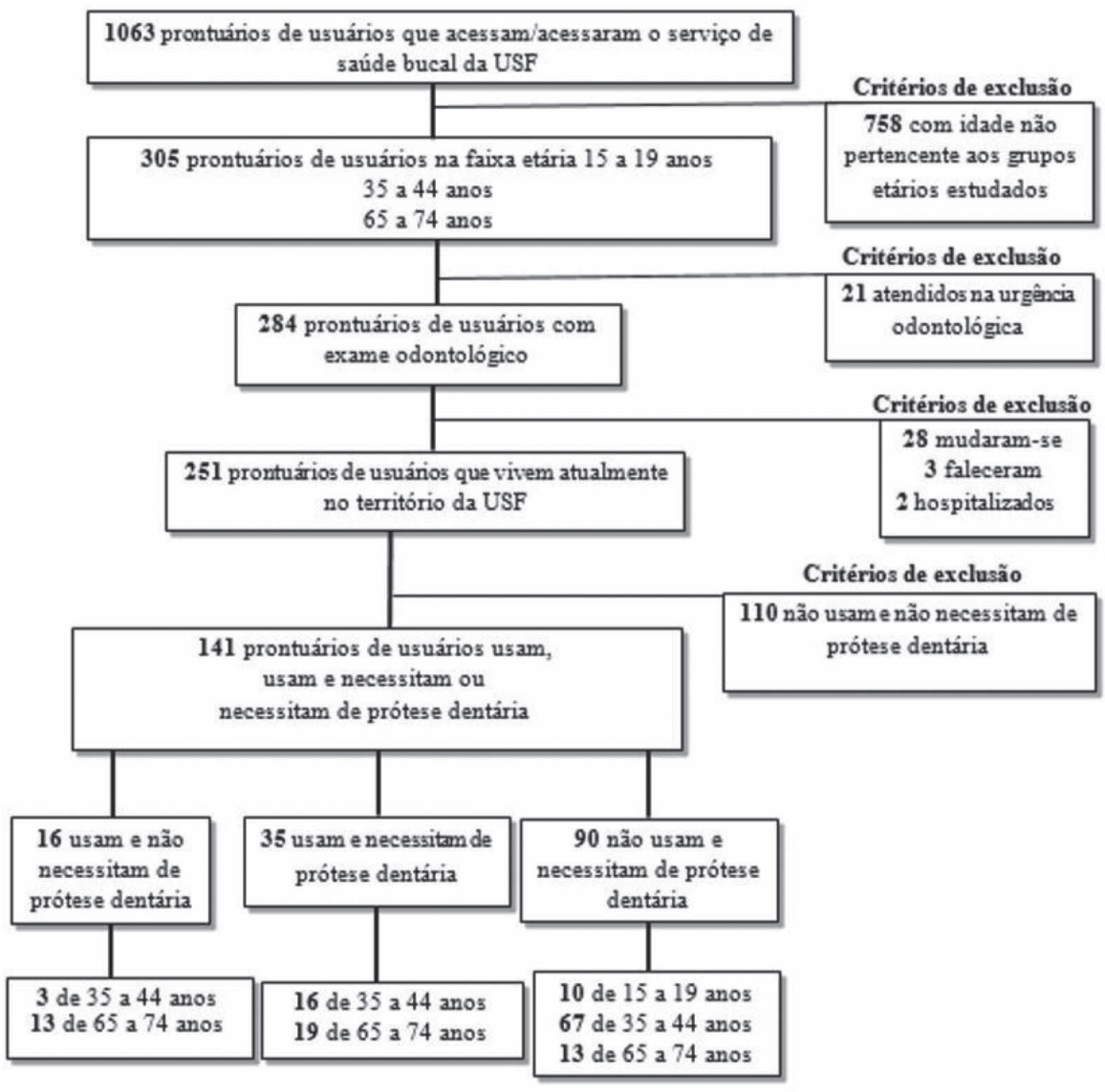

Fonte: Elaboração própria. 


\section{Entrevistas domiciliares}

Para a avaliação da autopercepção da saúde bucal, foram realizadas entrevistas individuais, semiestruturadas, seguindo um roteiro previamente testado, gravadas em equipamento de áudio e posteriormente transcritas na íntegra.

As entrevistas foram conduzidas com base em estrutura flexível, sendo realizadas por dois pesquisadores qualificados para pesquisa qualitativa, da área da Odontologia. A construção do roteiro das entrevistas (questôes norteadoras abertas) levou em consideração o instrumento que avaliou a autopercepção de saúde bucal nos dois últimos levantamentos epidemiológicos nacionais (BRASIL, 2004; 2011), com adaptaçôes para uma pesquisa de abordagem qualitativa, permitindo às pessoas relatarem suas experiências de vida envolvendo a saúde da boca e dos dentes, além das percepções sobre mastigação, fala, relações pessoais e satisfação com os dentes/próteses/boca.

Foram convidados a participar das entrevistas os usuários do serviço de saúde bucal da USF estudada, nas faixas etárias selecionadas, que utilizavam e/ou necessitavam de prótese dentária. A amostra foi intencional, seguindo o critério de fechamento amostral por saturação (FONTANELLA et al., 2011). À medida que os pesquisadores observaram que havia repetições de temáticas nas entrevistas, e considerando a densidade do material coletado, decidiu-se pelo encerramento da coleta de dados. Assim, 70 indivíduos foram entrevistados, totalizando cerca de 10 horas de gravação.

As entrevistas aconteceram na residência dos usuários (entrevistas domiciliares) entre os meses de abril e dezembro de 2014, sempre acompanhadas por Agentes Comunitários de Saúde.

O material textual obtido nas entrevistas e diário de campo foi importado para o software ATLAS.ti (Visual Qualitative Data Analysis) e interpretado por meio da análise de conteúdo proposta por Bardin (2011), compreendendo as seguintes etapas: pré-análise; exploração do material, tratamento dos resultados, inferência e interpretação.

\section{Resultados e discussão}

Os 70 usuários do serviço de Atenção Primária entrevistados eram, em sua maioria, mulheres, nas faixas etárias de 35 a 44 anos e 65 a 74 anos (tabela 1). 


\begin{tabular}{lllll}
\hline \multirow{2}{*}{ VARIÁVEIS } & \multicolumn{3}{c}{ IDADE (ANOS) } & \\
\cline { 2 - 4 } & $15-19$ & $35-44$ & $\mathbf{6 5 - 7 4}$ & \\
\hline SEXO & & & & \\
Feminino & 3 & 25 & 24 & $\mathbf{5 2}$ \\
Masculino & 2 & 5 & 11 & $\mathbf{1 8}$ \\
\hline USO DE PRÓTESE & & & & \\
\hline Sim & -- & 1 & 10 & $\mathbf{1 1}$ \\
\hline NECESSIDADE DE PRÓTESE & & & & \\
\hline Sim & 5 & 22 & 10 & $\mathbf{3 7}$ \\
\hline USO E NECESSIDADE DE PRÓTESE & & & & \\
\hline Sim & -- & 7 & 15 & $\mathbf{2 2}$ \\
\hline TOTAL & 5 & 30 & 35 & $\mathbf{7 0}$ \\
\hline
\end{tabular}

Fonte: Elaboração própria.

As percepções, histórias e sentimentos dessas pessoas em relação a sua saúde bucal são apresentados em três categorias que emergiram nas entrevistas: Entendendo o sentido do uso das próteses dentárias na vida de adultos e idosos; compreensão dos significados da perda dentária e sua relação com aspectos do viver humano: a pluralidade de olhares; da necessidade/desejo pela reabilitação ao desafio do acesso à prótese.

Buscou-se não só uma apresentação descritiva dos resultados, mas uma análise sobre a compreensão do significado da saúde bucal, relacionando-a ao uso/ necessidade de prótese dentária, em um diálogo constante entre os referenciais teóricos consultados e as subjetividades dos entrevistados.

\section{Entendendo o sentido do uso das próteses dentárias na vida de adultos e idosos}

Entre os indivíduos entrevistados que usavam próteses, a maior parte encontravase na faixa etária de 65 a 74 anos, e um número menor tinha de 35 a 44 anos. Nenhum adolescente entrevistado usava prótese. 
Nesses indivíduos adultos e idosos que percebiam as próteses usadas como bem adaptadas, não machucando a boca e não interferindo na mastigação, fala, comunicação e aparência, a autopercepção da saúde bucal foi positiva (usuários satisfeitos com sua saúde bucal), conforme observado nos relatos abaixo:

Não tem o que mudar, as próteses estão bem, se eu não tivesse elas seria difícil até para mastigar, para comer, mas está tudo certo com elas. Ficou bem as duas próteses. Não me atrapalham para falar. Não é difícil de comer, não tenho problema. (Homem, 67 anos, usa PT superior e PPR inferior e não necessita de prótese).

Esse meu dente [a prótese] é perfeito, é bem firme, não cai [...]. Eu consigo falar. Eu como até maçã com casca, posso comer de tudo, não solta, é bem firme. [...] todo mundo pensa que eu tenho dente normal, só quando eu falo que ele não é natural, porque não aparece gengiva nem nada. (Mulher, 43 anos, usa PT superior e não necessita de prótese).

Tal percepção positiva esteve presente tanto entre os indivíduos edêntulos, usuários de prótese total, quanto entre os edêntulos parciais, usuários de prótese parcial removível, achados semelhantes aos de Furtado, Forte e Leite (2011), em idosos institucionalizados que usavam próteses. Independente do fato desses idosos estarem desdentados total ou parcialmente, o mais importante era que as próteses estivessem funcionando de maneira adequada, sem causar incômodo e em bom estado de uso.

Outro aspecto importante enfatizado na fala dos usuários de próteses deste estudo foi a valorização, o sentido da reabilitação bucal pelo uso de próteses dentárias em suas vidas e as diferenças observadas a partir do uso da prótese (sem a prótese, havia problemas para comer, falar, doía, sentimento de vergonha, constrangimento).

A prótese faz muita diferença. Faz diferença total pra comer. Eu tinha vergonha de falar, era tímida. (Mulher, 36 anos, usa PPR superior e necessita de PPR inferior).

[...] antes eu não poderia falar com ninguém, eu tinha que mandar embora, se eu pudesse mandar embora, porque aquilo me doía, assim... Quando me doía, me afetava, mas agora não. (Mulher, 71 anos, usa PT dupla e não necessita de prótese).

Eu não fico perto de ninguém sem os dentes [a prótese]. Estou sempre com os dentes, eu não sei nem dizer como seria ficar perto dos outros sem os dentes. Eu acho que qualquer pessoa que fica sem os dentes, fica assim falando feito boba, não dá. Eu já tive uma ocasiāo que fiquei hospitalizada pra fazer exames e eles tiraram os dentes da gente, mas aí para falar ... [...] sem as próteses a gente se sente totalmente constrangida [...] Deus me livre! Aí sim, eu vou tapar a boca. (Mulher, 74 anos, usa PPR dupla e não necessita de prótese). 
Por outro lado, quando as próteses causavam incômodos durante a alimentação, machucando a boca, dificultando a mastigação, a fala e restringindo o consumo de determinados alimentos, as pessoas compreendiam que sua saúde bucal era afetada e consideravam-na como insatisfatória.

Quando mastigo algum alimento que tenha farelinhos, por exemplo, um bife à milanesa, porque tem os farelinhos, aí aqueles farelinhos se alojam embaixo da prótese, então tem que imediatamente tirar, porque o farelinho que fica na parte interna, ah incomoda! (Mulher, 74 anos, usa PPR dupla e não necessita de prótese).

Eu era bem nova quando coloquei a prótese de cima, mas eu sempre me acostumei. Agora a prótese está muito frouxa, a gente vai perdendo a gengiva e tudo vai ficando mais frouxo. Ela [a prótese] está solta na boca, se eu assoprar com força cai. É claro que a gente se sente mal porque fica feio, então não como nada fora de casa. Até para comer um pão ela sai do lugar (Mulher, 72 anos, usa PT superior e necessita de PT inferior).

[...] A chapa não firma, não pára na boca, eu me sinto meio ruim, falo mal. Hoje eu coloquei “Corega ${ }^{\circledR}$ ", ela está mais firme e eu estou falando. (Homem, 73 anos, usa PT superior e necessita de PT inferior).

Aliam-se a esses aspectos limitadores da mastigação, a dor, o incômodo e a vergonha ao se alimentarem na frente de outras pessoas, causando uma “incapacidade bucal” (GILBERT; FOERSTER; DUNCAN, 1998).

A prótese está dando buracos no céu da boca. [...] entra a comida e machuca o céu da boca ou embaixo a gengiva. [...] daí eu paro de comer [..] sair pra comer, me envergonha. Não tem como. É horrível. Por causa que dá essa infecção na boca, por causa da prótese que é frouxa e eu me sinto envergonhada com a prótese ruim assim, tu conversa com alguém tem que estar segurando ela no céu da boca. Não tenho do que rir. Vou mostrar o quê? Essa coisa horrível? Daí eu fico insatisfeita. (Mulher, 67 anos, usa PT superior e PPR inferior e não necessita de prótese).

Próteses inadequadas, mal adaptadas são determinantes para a autopercepção negativa da condição de saúde bucal, uma vez que podem gerar danos em tecidos moles e duros da cavidade bucal, comprometendo a saúde geral das pessoas pela perda da eficiência mastigatória, colocando em risco a qualidade nutricional da dieta (CASOTTI; MARTINS; FRANCISCO, 2012; UNFER et al., 2006). O sentimento de vergonha por conta da condição bucal pela perda dentária também se soma aos impactos negativos na qualidade de vida (SILVA et al., 2010).

Em idosos, de modo especial, alterações na capacidade mastigatória associamse, na maioria das vezes, a próteses totais ou parciais mal adaptadas ou em péssimo estado de conservação, além da ausência de dentes (MARCIAS, 2008). 
Independentemente do tipo de prótese usada, é preciso avaliar como as pessoas percebem a funcionalidade dessas próteses, característica determinante para a autopercepção da saúde bucal nos adultos e idosos deste estudo.

\section{Compreensão dos significados da perda dentária e sua relação com aspectos do viver humano: a pluralidade de olhares}

Para além das implicações fisiológicas, os significados da perda dos dentes irão variar de acordo com a relação do indivíduo com seu corpo e com o grupo social a que pertence. As expectativas e as representações dessas ausências sinalizam a necessidade de múltiplos olhares para compreender suas consequências no cotidiano da vida das pessoas e dos grupos (FERREIRA et al., 2006).

Neste estudo, os relatos dos usuários da Atenção Primária expressaram, em um primeiro momento, o lugar importante que a boca ocupa na vida das pessoas, pela relação com o sorriso, comunicação, interação com as pessoas e aparência pessoal.

O sorriso da gente é o cartão de visita, se não está adequado eu acho que tu não vai sorrir direito, não vai conversar direito, não vai interagir com as pessoas da mesma forma, então afeta bastante. (Mulher, 42 anos, usa PPR superior e necessita de PPR inferior).

A minha boca, os meus dentes são tudo! Se eu não tenho dentes bonitos, aí acaba com a pessoa. (Mulher, 38 anos, não usa prótese e necessita de PPR superior).

Quando a perda dentária era parcial e não afetava a aparência, nem a mastigação e a fala e não causava dor, essa ausência foi amenizada e pareceu não interferir nas relações sociais entre os indivíduos adolescentes e adultos estudados.

Eu acho que por mais que faltem os dentes aqui, eu mastigo bem, por isso que eu não tenho grandes dificuldades. [...] Sentir a falta dos dentes a gente sente, porque até mesmo tem que ter um embaixo e um em cima, mas eu como normal. [...] A pessoa está olhando a tua aparência e está normal aqui na frente, talvez, quando a gente sorri, abre a boca demais, a pessoa vai olhar, claro, mas ninguém falou nada sobre isso pra mim. (Mulher, 36 anos, não usa prótese e necessita de PPR inferior).

Eu não tenho dor de dente, não tenho nada, nem reclamação. Os dentes estão normais, estão sempre brancos, não estão amarelados, não incomoda. O dente que falta não incomoda nem um pouco, não sinto falta, até para morder, mastigar, nada, ele é quase o último, então não faz diferença nem para comer. (Mulher, 19 anos, não usa prótese e necessita de PPR superior).

Eu não sinto dor, nem nada, nada me impede de comer, mesmo sem esses dentes, eu como qualquer coisa, eu como normal. Eu tirei tudo que tinha que tirar que estava me incomodando, o que interfere é a questão da dor. Eu não tenho dor, para mim está ótimo, mesmo que falte os dentes. [...] eu tento ao máximo cuidar os dentes da 
Estudo de Carvalho et al. (2011) com adolescentes mostrou que dos fatores que influenciaram a autopercepção da saúde bucal nesse grupo, a má posição dentária foi o mais relevante, sendo que a maioria percebeu sua saúde bucal como boa e ótima e se considerou saudável, fato também percebido neste estudo.

Apesar dessa percepção positiva, as perdas dentárias em adolescentes são evitáveis em grande parte dos casos, mostrando a necessidade de atenção pelos serviços odontológicos aos grupos de indivíduos afetados. A manutenção funcional na adolescência pode se constituir em medidas preventivas de maiores agravos na fase adulta (BARBATO; PERES, 2009).

Já na percepção dos idosos, a ausência de dentes é percebida, mas quando comparada com problemas relacionados à condição dos dentes - dente quebrado, que provocasse dor e incômodo - não houve relatos negativos em relação à condição da saúde bucal.

[...] antes eu tinha os dentes, estavam ruins os dentes, aí tive que extrair os poucos que tinha e depois que coloquei as próteses, uma beleza. Para falar é normal, é ótimo. Uma coisa que eu nunca sinto é dor nos dentes. (Mulher, 67 anos, usa PT superior e PPR inferior e não necessita de prótese).

Eu tenho falta desses dentes aqui, se eu tivesse prótese, claro que seria melhor, mas não me prejudica. Como qualquer coisa. Eu não tenho nenhum problema. Falar, eu até falo demais. [...] Ah, se eu tivesse dente quebrado, sim [afetaria relacionamentos]. [...] eu estou muito satisfeita. Já pensou se me doesse, me incomodasse, tivesse quebrado, tivesse não sei o quê? Não tem nada disso. Como bem com os meus dentes, tá bom! (Mulher, 70 anos, não usa prótese e necessita de PPR dupla).

Esse fato pode ser explicado pela capacidade do idoso, de um modo geral, apresentar certa resiliência e tendência a se adaptar às condições de saúde não letais, podendo refletir na capacidade de se adaptar à deterioração da condição bucal durante o envelhecimento (AGOSTINHO; CAMPOS; SILVEIRA, 2015; MARTINS et al., 2011; LIMA et al., 2007; SILVA; FERNANDES, 2001).

Essa possibilidade de ouvir os usuários quanto à sua satisfação com relação à saúde bucal pode caracterizar-se como um componente estratégico de avaliação da qualidade dos serviços de saúde, permitindo oportunidades às pessoas para expressarem suas percepções em relação aos eles, o que fortaleceria sua participação nos processos de planejamento em saúde, promovendo o controle 
social no SUS (ESPERIDIÃO; TRAD, 2005). Sendo assim, assegura-se uma maior compreensão da apreciação dos serviços na ótica dos usuários, possibilitando a construção de ações com maior precisão nos fatores que devem ser melhorados nos serviços de saúde pública.

A presença de dor (na boca ou nos dentes) foi um fator diretamente associado à insatisfação com a condição de saúde bucal e autopercepção negativa, assim como relatado na literatura (VALE; MENDES; MOREIRA, 2013; BRAGA; BARRETO; MARTINS, 2012; LATHI; SUOMINENTAIPALE; HAUSEN, 2008).

É importante ressaltar que nem sempre a percepção da saúde bucal dos usuários entrevistados nesse estudo foi coincidente com a dos dentistas que cuidavam deles, conforme relato abaixo:

Olha, o doutor me falou que era bom colocar, ele disse que é por causa da mastigação. Mas eu não sei, me acostumei, não me atrapalha. Eu não sou de muito mastigar, eu mais dou umas mastigadinhas e vai. Eu acho que não está me atrapalhando. Eu pego uma maçã, descasco, mordo os pedaços, não tem problema nenhum. (Mulher, 69 anos, usa PT superior e necessita de PPR inferior).

De modo geral, os indivíduos são capazes de perceber sua condição bucal com alguma precisão, usando critérios diferentes do profissional (MENDONÇA; SZWARCWALD; DAMACENA, 2012). O profissional avalia a situação clínica por meio de parâmetros como a presença ou ausência de doença, enquanto que, para a população em geral, são mais significativos os sintomas e problemas sociais e funcionais advindos das doenças bucais.

Embora não possibilitem o diagnóstico de doenças ou substituição de exames clínicos que forneçam sinais objetivos das doenças, os aspectos subjetivos auxiliam no refinamento dos diagnósticos e na identificação de pessoas ou grupos populacionais em situação de vulnerabilidade (GABARDO; MOYSÉS; MOYSÉS, 2013), sendo mais uma ferramenta de avaliação que complementa as informações clínicas (JOKOVIC; LOCKER, 1997).

O conhecimento sobre a autopercepção de uma boa saúde bucal pode ser considerado um preditor importante da não necessidade de tratamento odontológico atual, uma vez que envolve subjetividades que deveriam ser consideradas no cuidado em saúde (MATOS; LIMA-COSTA, 2006).

Concorda-se com Gabardo et al. (2015) quando afirmam que variáveis individuais e contextuais estão associadas à autopercepção de saúde bucal, 
sendo essa informação imprescindível para o planejamento de serviços de saúde

bucal que pretendam atender às necessidades de saúde da população e reduzir as iniquidades em saúde bucal.

\section{Da necessidade/desejo pela reabilitação ao desafio do acesso à prótese}

Na perspectiva da perda dentária, a reabilitação bucal pela colocação de próteses foi vista, neste estudo, como uma possibilidade de melhoria na condição da mastigação e na estética de adultos e idosos.

Eu gostaria de uma prótese, [...] não aparece, mas fica chato sem o dente na boca. Com a prótese melhoraria a mastigação, porque eu tenho dois pra trás ainda. ( $\mathrm{Mu}$ lher, 38 anos, não usa prótese e necessita de PPR superior).

Eu pretendo até o fim do ano, estar com elas [próteses], porque já há tempo estava com vontade de fazer [...] pode melhorar um pouquinho a aparência se botar, que daí não fica com essas faltas aqui. (Mulher, 70 anos, não usa prótese e necessita de PPR dupla).

O desejo de reposição dos dentes naturais perdidos, no entanto, esbarrou no acesso a essa reabilitação pelo alto custo das próteses, o que levou os indivíduos a relatarem insatisfação com sua saúde bucal.

Eu pensei em colocar prótese, mas condições eu não tenho agora de colocar. (Mulher, 36 anos, não usa prótese e necessita de PPR inferior).

Eu tinha vontade de botar uma prótese desses seis dentes que faltam, mas não estou conseguindo, falta dinheiro. (Homem, 74 anos, não usa prótese e necessita PPR superior).

A mesma situação foi observada quando a reabilitação se referia à necessidade de substituir a prótese antiga, já sem condições adequadas de uso, por uma nova.

Tem que fazer outra, mas não tenho dinheiro. Tem que esperar até entrar um dinheiro. Economizar todo o mês dez 'contos'. Fui no dentista ali e ele quer mil e poucos reais, ganhando um salário mínimo de setecentos e vinte 'pila' o que tu quer que eu faça? E a comida está cara, como é que eu vou deixar de comer? (Mulher, 67 anos, usa PT dupla e necessita substituir as próteses).

Embora, normalmente, as pessoas expressem necessidades de tratamento protético quando da falta de dentes, fatores financeiros são relatados como os maiores empecilhos para colocação das próteses (TEÓFILO; LELES, 2007). Para esse grupo, a busca por serviços privados de alto custo é justificada pela ausência da oferta de reabilitação protética no serviço público de saúde. 
O que eu tinha pra fazer pelo posto o dentista fez e me liberou, porque prótese não é feito ali, só particular; eu vou tentar, mas tudo isso é muito caro, é um absurdo. (Mulher, 40 anos, não usa prótese e necessita de PPR inferior).

Eu estou totalmente insatisfeita por causa da função da 'ponte', porque eu preciso recorrer para o particular, a questão do dinheiro não dá [...] (Mulher, 35 anos, usa PPR superior e necessita de PPR inferior).

Ferreira et al. (2006), estudando as representaçôes sociais do cuidado à saúde bucal em uma população de baixa renda do Nordeste brasileiro, também encontraram relatos sobre o acesso limitado dessas pessoas às próteses dentárias, uma vez que estas não estavam disponíveis no serviço público. As dificuldades econômicas tornaram a aquisição das próteses inviável para essa população, deixando-as no plano imaginário.

Os mesmos problemas causados pela perda dentária e a falta de acesso à prótese dentária foram observados por Vargas e Paixão (2005) na população adulta usuária da Atenção Primária de Belo Horizonte, Minas Gerais. Os autores apontaram deficiências do serviço de saúde prestado ao adulto, com pouca resolutividade, já que não havia oferta de prótese dentária para a reabilitação estética e funcional dos pacientes, que não possuíam condiçõos econômicas de fazê-las na prática privada.

No contexto de falta de acesso à prótese dentária no serviço público, o nível econômico exerce um papel fundamental na permanência da condição desdentada das pessoas (SILVA; MAGALHĀES; FERREIRA, 2010).

Para suprir essa necessidade, uma das alternativas encontradas pelos usuários pesquisados foi a procura por serviços não habilitados, como "protéticos" conhecidos que acabavam oferecendo a prótese por um preço mais acessível, conforme relatado por um usuário:

[...] um conhecido me falou de um protético que faz a chapa bem baratinho, ele é bem conhecido e tem boa fama (Registro do diário de campo).

Nesse sentido, é fundamental uma reflexão a partir do contexto das políticas de saúde do Brasil. Os avanços obtidos no plano legal, assegurando saúde como direito, são inegáveis. Regulamentado pela Constituição de 1988, o Sistema Único de Saúde (SUS), considerado uma das maiores conquistas sociais do país, é constituído por princípios doutrinários - universalidade, equidade e integralidade -, que apontam para a democratização nas ações e nos serviços 
de saúde (BRASIL, 2000). Acrescentam-se a esse cenário favorável a inclusão da equipe de saúde bucal na Estratégia Saúde da Família (BRASIL, 2001) e a implantação da Política Nacional de Saúde Bucal - Brasil Sorridente, em 2004 (BRASIL, 2004b).

Segundo Kornis, Maia e Fortuna (2011, p. 208-209):

[...] no balanço da última década, a prestação pública de serviços em saúde bucal avança de um panorama de oferta limitada de procedimentos de baixa complexidade com reduzida realização de procedimentos especializados, em direção à ampliação do acesso na atenção básica e na média complexidade.

Apesar desses avanços e considerando-se que o protocolo de Atenção em Saúde Bucal do município de Porto Alegre (PORTO ALEGRE, 2014) menciona a prótese dentária entre as atribuições da Equipe de Saúde Bucal na Atenção Primária, bem como apresenta a promoção do cuidado integral em todos os níveis de atenção, ainda se verifica um acesso restrito à prótese dentária para essa população. Atualmente, Porto Alegre oferece o serviço de prótese dentária em apenas um Centro de Especialidades Odontológicas, que atende usuários de uma área específica de cobertura (GRUPO HOSPITALAR CONCEIÇÃO, 2015).

A falta de acesso à prótese dentária afeta o princípio da integralidade, comprometendo também os princípios da universalidade e da equidade. $\mathrm{O}$ cuidado em saúde deve abarcar suas diversas dimensões. Analogamente, deve oferecer respostas aos diversos grupos atingidos pelos problemas apresentados (MATTOS, 2006), o que não acontecerá sem a possibilidade do acesso à prótese dentária.

É importante mencionar que a Política Nacional de Saúde Bucal destaca o direito do cidadão e o dever do Estado de garantir a prótese dentária. No contexto da Atenção Primária, o acesso à prótese avançaria na superação do quadro atual, em que procedimentos relativos às próteses dentárias então inseridos nos serviços especializados e, portanto, não são acessíveis à maioria da população (BRASIL, 2004b). A saúde pública deve oferecer essa acessibilidade, reconhecendo a cidadania e percebendo os sujeitos como "cidadãos de direito e donos de uma capacidade crítica de reflexão e de eleição mais autônoma de modos de levar a vida" (CAMPOS, 2000, p. 229).

A ampliação do acesso ao serviço de prótese dentária no SUS é uma necessidade real e de grande relevância no contexto nacional (MURAKAMI; MOYSÉS; MOYSÉS, 2007), o que também se observa em Porto Alegre. 


\section{Considerações finais}

Foram observadas diferenças nas narrativas entre os jovens (15-19 anos), adultos (35-44 anos) e idosos (65-74 anos) no que se referiu às categorias analisadas. A autopercepção positiva da saúde bucal, expressa pela satisfação dos usuários com sua boca e dentes, foi relatada por adultos e idosos usuários de próteses que as percebiam como bem adaptadas, não machucando a boca e não interferindo na mastigação, na fala e na comunicação. Nesse grupo, houve grande valorização do uso de próteses pela possibilidade da reabilitação bucal. As narrativas mostraram melhorias na vida das pessoas a partir do uso de próteses e um sentimento de vergonha, constrangimento, se tivessem que ficar sem esses dentes artificiais. Já próteses consideradas pelos entrevistados como inadequadas, mal adaptadas e incômodas foram determinantes para a autopercepção negativa da saúde bucal. Nenhum adolescente entrevistado usava prótese.

A perda dentária parcial que não afetava a aparência, mastigação, fala e não causava dor, pareceu não interferir nas relações sociais entre os indivíduos adolescentes e adultos estudados. Para os idosos, a ausência de dentes foi percebida, mas, quando comparada com problemas relacionados à condição dos dentes (dente quebrado, que provocasse dor e incômodo), não houve relatos negativos em relação à saúde bucal.

A reabilitação bucal pela colocação de próteses foi vista, por adultos e idosos com perda dentária e necessidade de prótese, como uma possibilidade de melhoria na condição mastigatória e estética. Esse desejo de reposição dos dentes naturais perdidos, no entanto, esbarrou no alto custo das próteses no serviço privado e na oferta limitada de tal procedimento no serviço público do município estudado.

A compreensão de como usuários da Atenção Primária que usam e/ou necessitam de prótese dentária percebem sua saúde bucal, por meio de uma avaliação qualitativa, apresenta-se como uma importante ferramenta complementar na avaliação da necessidade de tratamento odontológico, permitindo analisar o significado da saúde bucal na perspectiva dos usuários do SUS.

Informações que contemplem as subjetividades das pessoas são imprescindíveis para um planejamento de ações da equipe de Atenção Primária/Saúde da Família que pretenda atender às necessidades da população, devendo ser consideradas no processo do cuidado integral em saúde. 
Com base nas narrativas analisadas de usuários da Atenção Primária sobre sua

saúde bucal, chama-se a atenção para a necessidade da ampliação do acesso ao serviço de prótese dentária pelo SUS em Porto Alegre. ${ }^{12}$

\section{Referências}

AGOSTINHO, A. C. M. G.; CAMPOS, M. L.; SILVEIRA, J. L. G. C. Edentulismo, uso de prótese e autopercepção de saúde bucal entre idosos. Rev. Odontol. UNESP. São Paulo, v. 44, n. 2, p. 74-79, 2015.

ALMEIDA, J. R. S. et al. Autopercepção de pessoas acometidas pela hanseníase sobre sua saúde bucal e necessidade de tratamento. Ciênc. Saúde Coletiva. Rio de Janeiro, v. 18, n. 3, p. 817-826, 2013.

BARBATO, P. R.; PERES, M. A. Perdas dentárias em adolescentes brasileiros e fatores associados: estudo de base populacional. Rev. Saúde Pública. São Paulo, v. 43, n. 1, p. 13-25, 2009.

BARDIN, L. Análise de conteúdo. São Paulo: Edições 70, 2011.

BOMBARDA-NUNES, F. F.; MIOTTO, M. H. M. B.; BARCELlOS, L. A. Autopercepção de saúde bucal do agente comunitário de saúde de Vitória, ES, Brasil. Pesqui. Bras. Odontopediatria Clín. Integr. João Pessoa, v. 8, n. 1, p.7-14, jan./abr. 2008.

BOTAZZO, C. Sobre a bucalidade: notas para a pesquisa e contribuição ao debate. Ciênc. Saúde Coletiva. Rio de Janeiro, v. 11, n. 1, p. 7-17, 2006.

BRAGA, A. P. G.; BARRETO, S. M.; MARTINS, A. M. E. D. B. L. Autopercepção da mastigação e fatores associados em adultos brasileiros. Cad. Saúde Pública. Rio de Janeiro, v. 28, n. 5, p. 889-904, 2012.

BRASIL. Ministério da Saúde. Secretaria Executiva. Sistema Único de Saúde (SUS): princípios e conquistas. Brasília: 2000.

Portaria no. 267, de 6 de março de 2001. Brasília, 2001. Disponível em: < http:// dtr2004.saude.gov.br/susdeaz/legislacao/arquivo/32_Portaria_267_de_06_03_2001.pdf >. Acesso em: 19 jul. 2015.

Secretaria de Atenção à Saúde. Departamento de Atenção Básica. Projeto SB Brasil 2003: condiçôes de saúde bucal da população brasileira 2002-2003: resultados principais. Brasília, 2004a. Disponível em: <http://bvsms.saude.gov.br/bvs/publicacoes/projeto_ sb2004 >. Acesso em: 9 jun. 2015.

Secretaria de Atenção à Saúde. Departamento de Atenção Básica. Coordenação Nacional de Saúde Bucal. Diretrizes da Política Nacional de Saúde Bucal. Brasília, 2004b. Disponível em: <http://conselho.saude.gov.br/web_comissoes/cisb/doc/politica_nacional. pdf $>$. Acesso em 30 de jun. 2015. 
- Projeto SB Brasil 2010: Pesquisa Nacional de Saúde Bucal 2010. Resultados principais. Brasília, 2011. Disponível em: <http://dab.saude.gov.br/CNSB/sbbrasil/ arquivos/projeto_sb2010_relatorio_final.pdf>. Acesso em: 2 jun. 2015.

CAMPOS, G. W. S. Saúde pública e saúde coletiva: campo e núcleo de saberes e práticas. Ciênc. Saúde Coletiva. Rio de Janeiro, v. 5, n. 2, p. 219-230, 2000.

CARVALHO, R. W. F. et. al. Aspectos psicossociais dos adolescentes de Aracaju (SE) relacionados à percepção de saúde bucal. Ciênc. Saúde Coletiva. Rio de Janeiro, v. 16, n. supl.1, p. 1621-1628, 2011.

CASOTTI, C. A.; MARTINS, K.; FRANCISCO, S. Self-perception and oral health conditions of the elderly in a small town. Rev. Gauch. Odontol. Porto Alegre, v. 60, n. 2, p. 187-193, 2012.

ESMERIZ, C. E. C.; MENEGHIM, M. C.; AMBROSANO, G. M. B. Self-perception of oral health in non-institutionalised elderly of Piracicaba city, Brazil. Gerodontology. Basel, v. 29, p. 281-289, 2012.

ESPERIDIAO, M.; TRAD, L. A. B. Avaliação de satisfação de usuários. Ciênc. Saúde Coletiva. Rio de Janeiro, v.10, supl. 1, p. 303-312, 2005.

FERREIRA, A. A. A. et al. A dor e a perda dentária: representações sociais do cuidado à saúde bucal. Ciênc. Saúde Coletiva. Rio de Janeiro, v. 11, n. 1, p. 211-218, 2006.

FONTANELLA, B. J. B. et al. Amostragem em pesquisas qualitativas: proposta de procedimentos para constatar saturação teórica. Cad. de Saúde Pública. Rio de Janeiro, v. 27, n. 2, p.389-394, fev. 2011.

FURTADO, D. G.; FORTE, F. D. S.; LEITE, D. F. B. M. Uso e necessidade de próteses em idosos: reflexos na qualidade de vida. Rev. Bras. Ciênc. Saúde. João Pessoa, v. 15, n. 2, p. 183-190, 2011.

GABARDO, M. C. L. et al. Multilevel analysis of self-perception in oral health and associated factors in Southern Brazilian adults: a cross-sectional study. Cad. Saúde Pública. Rio de Janeiro, v. 31, n. 1, p. 49-59, 2015.

GABARDO, M. C. L.; MOYSÉS, S. T.; MOYSÉS, S. J. Autopercepção de saúde bucal conforme o Perfil de Impacto da Saúde Bucal (OHIP) e fatores associados : revisão sistemática. Rev. Panam. Salud Pública. Washington, v. 33, n. 7, p. 439-445, 2013.

GILBERT, G. H.; FOERSTER, U.; DUNCAN, R. P. Satisfaction with chewing ability in a diverse sample of dentate adults. J. Oral Rehabil. Oxford, v. 25, p. 15-27, 1998.

GRUPO HOSPITALAR CONCEIÇÃO. Carta ao cidadão Grupo Hospitalar Conceição. Porto Alegre, 2015. Disponível em: <http://www.ghc.com.br/files/cartacidadao.pdf>. Acesso em: 8 jun. 2015. 
HAIKAL, D. S. et al. Autopercepção da saúde bucal e impacto na qualidade de vida do idoso : uma abordagem quanti-qualitativa. Ciênc. Saúde Coletiva. Rio de Janeiro, v. 16, n. 7, p. 3317-3329, 2011.

JOKOVIC, A.; LOCKER, D. Dissatisfaction with oral health status in an older adult population. J. Public Health Dent. Raleigh, v. 57, n. 1, p.40-47, 1997.

KORNIS, G. E. M.; MAIA, L. S.; FORTUNA, R. F. P. Evolução do financiamento da atenção à saúde bucal no SUS: uma análise do processo de reorganização assistencial frente aos incentivos federais. Physis: REvista de Saúde Coletiva. Rio de Janeiro, v. 21, n. 1, p. 197215, 2011.

LAHTI, S.; SUOMINEN-TAIPALE, L.; HAUSEN, H. Oral health impacts among adults in Finland: Competing effects of age, number of teeth, and removable dentures. Eur. J. Oral Sci. Copenhagen, v. 116, n. 4, p. 260-266, 2008.

LIMA, L. H. M. A. et al. Autopercepção oral e seleção de alimentos por idosos usuários de próteses totais. Rev. Odontol. UNESP. São Paulo, v. 36, n. 2, p. 131-136, 2007.

LOCKER, D. Self-esteem and socioeconomic disparities in self-perceived oral health. $J$. Public Health Dent. Raleigh, v. 69, n. 1, p. 1-8, 2009.

MARCIAS, A. V. G. Avaliação das condições de saúde bucal em idosos asilados no município de Campos - RJ. 2008. 81 f. Dissertação (Mestrado em Saúde Pública) - Escola Nacional de Saúde Pública Sergio Arouca, Rio de Janeiro, 2008.

MARTINS, A. B. et al. Resilience and Self-Perceived Oral Health: A Hierarchical Approach. J. Am. Geriatr. Soc. New York, v. 59, no. 4, p. 725-731, Apr. 2011.

MARTINS, A. M. E. D. B. L. et al. Autopercepção da saúde bucal entre idosos brasileiros. Rev. Saúde Pública. São Paulo, v. 44, n. 5, p. 912-922, 2010.

MARTINS, A. M. E. D. B. L. et al. Uso de serviços odontológicos por rotina entre idosos brasileiros: projeto SB Brasil. Cad. Saúde Pública. Rio de Janeiro, v. 24, n.7, p. 1651-1666, jul. 2008.

MARTINS, A. M. E. B. L.; BARRETO, S. M.; PORDEUS, I. A. Fatores relacionados à autopercepção da necessidade de tratamento odontológico entre idosos. Rev. Saúde Pública. São Paulo, v. 42, n. 3, p. 487-496, 2008.

MATOS, D. L.; LIMA-COSTA, M. F. Autoaavaliação da saúde bucal entre adultos e idosos residentes na Regiāo Sudeste: resultados do Projeto SB-Brasil, 2003. Cad. Saúde Pública. Rio de Janeiro, v. 22, n. 8, p. 1699-1707, ago. 2006.

MATTOS, R. A. Os sentidos da integralidade: algumas reflexões acerca de valores que merecem ser defendidos. In: PINHEIRO, R. P.; MATTOS, R. A. (Org.). O sentido da integralidade na atenção e no cuidado à saúde. Rio de Janeiro: Cepesc, 2006. p. 43-67. 
MENDONÇA, H. L. C.; SZWARCWALD, C. L.; DAMACENA, G. N. Autoavaliação de saúde bucal: resultados da Pesquisa Mundial de Saúde - Atenção Básica em quatro municípios do Estado do Rio de Janeiro, Brasil, 2005. Cad. Saúde Pública. Rio de Janeiro, v. 28, n. 10, p. 1927-1938, 2012.

MOREIRA, R. S. et al. A saúde bucal do idoso brasileiro: revisão sistemática sobre o quadro epidemiológico e acesso aos serviços de saúde bucal. Cad. Saúde Pública. Rio de Janeiro, v. 21, n. 6, p. 1665-1675, 2005.

MURAKAMI, A. M. U.; MOYSES S. J.; MOYSES S. T. Equidade frente à necessidade de prótese dentária na população de 65 a 74 anos de idade em Curitiba. Epidemiol. Serv. Saúde. Brasília, v. 16, n. 2, p. 139-141, 2007.

PIUVEZAN, G.; FERREIRA, A. A. A.; ALVES, M. S. C. Enfrentando as perdas dentárias na terceira idade: um estudo de representações sociais. Cad. Saúde Coletiva. Rio de Janeiro, v. 14, n. 4, p. 597-614, 2006.

PORTO ALEGRE. Secretaria Municipal de Saúde. Área Técnica de Saúde Bucal. Protocolo de atenção em saúde bucal de Porto Alegre: organização da rede e fluxos de atendimentos, out. 2014. Disponível em: <http://lproweb.procempa.com.br/pmpa/prefpoa/sms/usu_doc/ protocolosaudebucal2014.pdf>. Acesso em: 19 jul. 2015.

SCALCO, G. P. C. et al. Occupational stress and self-perceived oral health in Brazilian adults: a Pro-Saúde study. Ciênc. Saúde Coletiva. Rio de Janeiro, v. 18, n. 7, p. 2069-2074, 2013.

SILVA, S. R. C.; FERNANDES, R. A. C. Autopercepção das condições de saúde bucal por idosos. Rev. Saúde Pública. São Paulo, v. 35, n. 4, p. 349-355, 2001.

SILVA, D. D.; SOUSA, M. L. R.; WADA, R. S. Autopercepção e condições de saúde bucal em uma população de idosos. Cad. Saúde Pública. Rio de Janeiro, v. 21, n. 4, p. 1251-1259, 2005. SILVA, S. R. C.; ROSELL, F. L.; VALSECKI JÚNIOR, A. V. Percepção das condições de saúde bucal por gestantes atendidas em uma unidade de saúde no município de Araraquara, São Paulo, Brasil. Rev. Bras. Saúde Matern. Infant. Recife, v. 6 n. 4, p. 405410, out./dez. 2006.

SILVA, M. E. S. et al. Impacto da perda dentária na qualidade de vida. Ciênc. Saúde Coletiva. Rio de Janeiro, v. 15, n. 3, p. 841-850, 2010.

SILVA, M. E. S.; MAGALHÃES, C. S.; FERREIRA, E. F. Perda dentária e expectativa da reposição protética: estudo qualitativo. Ciênc. Saúde Coletiva. Rio de Janeiro, v. 15, n. 3, p. 813-820, 2010.

SILVA, D. D. et al. Autopercepção da saúde bucal em idosos e fatores associados em Campinas, SP, 2008-2009. Rev. Saúde Pública. São Paulo, v. 45, n. 6, p. 1145-1153, 2011.

TEÓFILO, L. T.; LELES, C.R. Patients' self-perceived impacts and prosthodontic needs at the time and after tooth loss. Braz. Dent. J. Ribeirão Preto, v. 18, n. 2, p. 91-96, 2007. 
UNFER, B. et al. Autopercepção da perda de dentes em idosos. Interface - Comun. Saúde Educ. Botucatu, v. 10, n. 19, p. 217-226, 2006.

VALE, E. B.; MENDES, A. D. C. G.; MOREIRA, R. D. S. Autopercepcao da saude bucal entre adultos na regiao Nordeste do Brasil. Rev. Saúde Pública., São Paulo, v. 47, supl. 3, p. 98-108, 2013.

VARGAS, A. M. D.; PAIXÃO, H. H. Perda dentária e seu significado na qualidade de vida de adultos usuários de serviço público de saúde bucal do Centro de Saúde Boa Vista, em Belo Horizonte. Ciênc. Saúde Coletiva. Rio de Janeiro, v.10, n. 4, p. 1015-1024, 2005.

VASCONCELOS, L. C. A. et al. Autopercepção da saúde bucal de idosos de um município de médio porte do Nordeste brasileiro. Cad. Saúde Pública. Rio de Janeiro, v. 28, n. 6, p. 1101-1110, jun. 2012.

YIN, R. K. Estudo de caso: planejamento e métodos. 4. ed. Porto Alegre: Bookman, 2010.

\section{Notas}

${ }^{1} \mathrm{H}$. W. Corrêa efetuou construção do referencial teórico, coleta de dados, transcrição das entrevistas, análise de dados, escrita do artigo. F. V. Bitencourt realizou construção do referencial teórico, coleta de dados, transcrição das entrevistas, análise de dados, escrita do artigo. A. V. Nogueira colaborou com a coleta e análise de dados, escrita e revisão do artigo. R. F. C. Toassi colaborou com a idealização e coordenação da pesquisa, construção do referencial teórico, revisão da transcrição das entrevistas, análise de dados, escrita e revisão final do artigo.

${ }^{2}$ Este estudo recebeu auxílio da Fundação de Amparo à Pesquisa do Estado do Rio Grande do Sul Fapergs (bolsa de iniciação científica) e fez parte de trabalho de conclusão de curso da graduação em Odontologia. 


\section{Abstract}

Oral health in primary care users: qualitative analysis of self-perceived associated to use and need of dental prosthesis

This qualitative study aimed to perceive the selfperception of oral health in users of Primary Care in Porto Alegre who use and/or need dental prosthesis. Data collection performed by odontology records analysis, field diaries and semi-structured home interviews with 70 health service users in age groups 15-19, 35-44 and 65-74 years who use and/or need dental prosthesis (intentional sample saturation). The reports of interviews were interpreted by Bardin thematic content analysis and ATLAS.ti software to support. The positive selfperception of oral health was perceived by adults and elderly who use well-fitting dental prosthesis that do not hurt the mouth and did not interfere in chewing, speech and communication. There was great appreciation of the use dental prosthesis for the possibility of oral rehabilitation. The desire of using dental prosthesis bumped in their high cost and limited access in the public service of the municipality. This information allows the analysis of the significance of oral health to Unified Health System users and can be used as a tool assessment need for dental treatment.

> Key words: self-concept; oral health; dental prosthesis; primary health care; qualitative research. 